\title{
Case Report: Case report: A rare case of middle-ear \\ Rhabdomyosarcoma in a 4-year-old boy [version 1; peer
}

\section{review: 3 approved]}

\author{
Richard Menzies-Wilson (iD1, Gentle Wong2, Prodip Das² \\ ${ }^{1}$ Urology Department, Whipps Cross University Hospital, London, UK \\ ${ }^{2}$ Ear, Nose and Throat Department, Brighton and Sussex University Hospitals, Brighton, UK
}

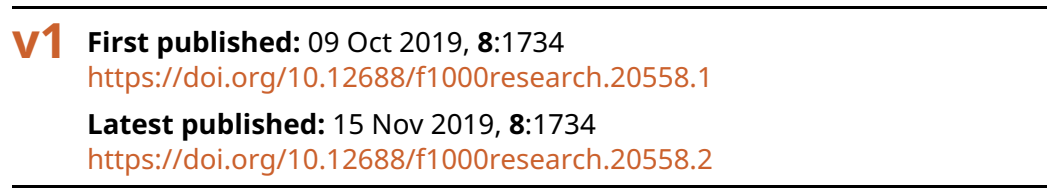

\section{Abstract}

We present a rare case of a four-year-old boy with a botyroid embryonal rhabdomyosarcoma of the right middle ear.

Rhabdomyosarcoma is a soft tissue malignancy which is thought to originate from embryonic mesenchymal cells of striated skeletal muscle. It is a disease primarily of children and is exceptionally rare in parameningeal regions. The diagnosis is often delayed and easily misdiagnosed as aural polyp. Therefore, advanced disease is common at the time of diagnosis. A four-year-old boy presented with a fourmonth history of recurrent left ear blood and pus discharge, otalgia and fevers. He attended his GP three times and paediatric A\&E 13 times where he received antibiotics for presumed otitis media and externa. He was eventually referred to the otolaryngology department and underwent an examination under anaesthesia of ear and excisional biopsy of a suspicious aural polyp. Staging chest CT and PET scan showed no loco-regional spread or distal metastasis. Magnetic resonance imaging demonstrated absence of invasion into adjacent organs. Histology confirmed embryonal rhabdomyosarcoma, botryoid subtype. Subsequent to the initial excision of the polyp, he was started on an ifosfamine, vincristine and actinomycin (IVA) chemotherapy regime in three weekly cycles for nine cycles with concomitant radiotherapy. Two weeks subsequent to his first chemotherapy dose he presented with a House-Brackmann IIIII facial nerve palsy but no other middle ear complications. He was started on intravenous antibiotics and dexamethasone. The facial nerve palsy incompletely resolved with treatment.

Keywords

Rhabdomyosarcoma, middle ear

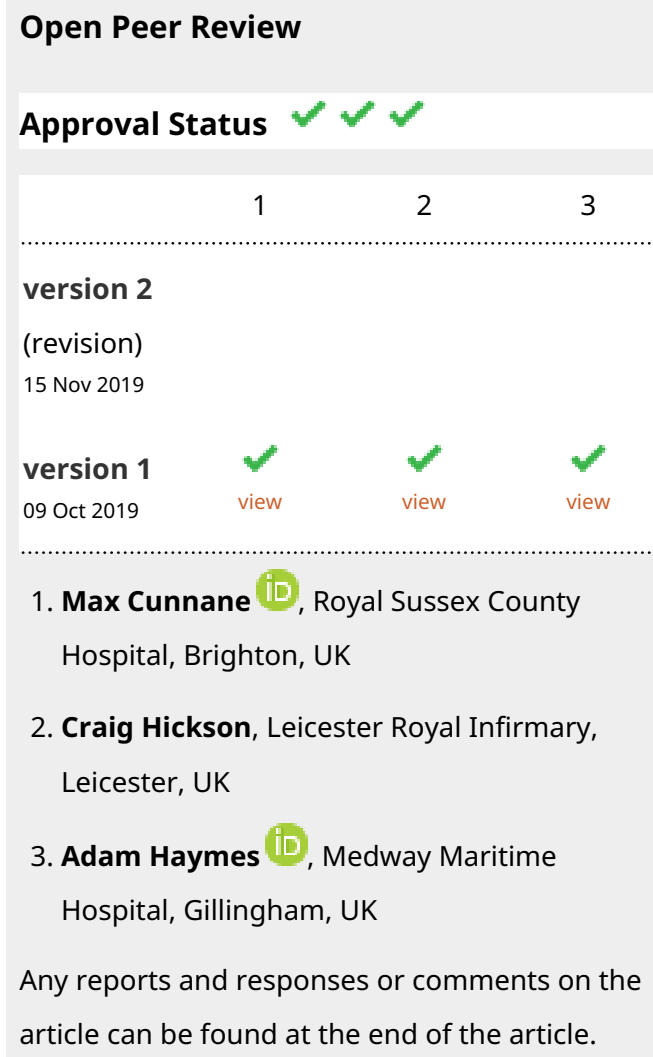

2. Craig Hickson, Leicester Royal Infirmary, Leicester, UK

3. Adam Haymes (D), Medway Maritime

Hospital, Gillingham, UK

Any reports and responses or comments on the article can be found at the end of the article. 
Corresponding author: Richard Menzies-Wilson (rmenzieswilson@gmail.com)

Author roles: Menzies-Wilson R: Writing - Original Draft Preparation; Wong G: Supervision, Writing - Review \& Editing; Das P: Conceptualization, Supervision, Writing - Review \& Editing

Competing interests: No competing interests were disclosed.

Grant information: The author(s) declared that no grants were involved in supporting this work.

Copyright: @ 2019 Menzies-Wilson R et al. This is an open access article distributed under the terms of the Creative Commons Attribution License, which permits unrestricted use, distribution, and reproduction in any medium, provided the original work is properly cited.

How to cite this article: Menzies-Wilson R, Wong G and Das P. Case Report: Case report: A rare case of middle-ear Rhabdomyosarcoma in a 4-year-old boy [version 1; peer review: 3 approved] F1000Research 2019, 8:1734

https://doi.org/10.12688/f1000research.20558.1

First published: 09 Oct 2019, 8:1734 https://doi.org/10.12688/f1000research.20558.1 


\section{Introduction}

Rhabdomyosarcoma is a rare soft tissue malignancy with unknown aetiology. It is thought to originate from embryonic mesenchymal cells of striated skeletal muscle. It is a disease primarily of children, with two-thirds of patients presenting under the age of six years ${ }^{1}$. The commonest areas of the body to be affected are the head and neck, the bladder and reproductive organs. They are rare elsewhere and are exceptionally rare in parameningeal regions, including the ear and mastoid.

Symptoms depend on the location of the tumour. Aural involvement often has non-specific symptoms such as fever and otalgia. If the tumour is significant in size and protrudes through the tympanic membrane, then otorrhoea and hearing loss may result. Rarely, facial nerve palsy may occur. The diagnosis is often delayed and easily misdiagnosed as aural polyp. Therefore, advanced disease is common at the time of diagnosis.

We present a rare case of a four-year-old boy with a botyroid embryonal rhabdomyosarcoma of the right middle ear and review the literature.

\section{Case report}

A four-year-old boy presented with a four-month history of recurrent left ear blood and pus discharge, otalgia and fevers. $\mathrm{He}$ attended his general practitioner (GP) three times and Paediatric Accident \& Emergency 13 times where he received oral, topical and intravenous antibiotics for presumed otitis media and externa. He had no relevant family history. He was eventually referred to the otolaryngology department after 19 months and was listed for an examination under anaesthesia of and excisional biopsy of a suspicious aural polyp 2 weeks after presentation to the otolaryngology department team. Intraoperatively, a large lesion extending from the middle ear through the tympanic membrane and into the external auditory canal was noted which was resected. The lesion was found to be highly vascular.

Histopathological findings were in keeping with embryonal rhabdomyosarcoma, botryoid subtype. This rare diagnosis required a second opinion from the Histology Department at the Royal Marsden Hospital. Immunochemical staining revealed sheets of rounded tumour cells with scant cytoplasm and inconspicuous nucleoli, which were distinguished by the formation of polypoid and grapelike tumour masses. Malignant cells in an abundant myxoid stroma were observed. Staining was positive for desmin and muscle-specific actin.

Magnetic resonance imaging (MRI) of the head was performed within two weeks of resection of the tumour, which demonstrated absence of invasion into adjacent organs. Staging chest MRI showed no evidence of metastases and PET scan showed no loco-regional spread or distal metastasis. Bone marrow trephine and CSF were negative. The patient's haemoglobin levels were borderline anaemic but all routine blood tests were otherwise within normal limits.
At 5 weeks after initial presentation he was started on nine cycles of IVA chemotherapy: ifosfamine $\left(3 \mathrm{~g} / \mathrm{m}^{2}\right.$ on days 1 and 2); vincristine $\left(1.5 \mathrm{mg} / \mathrm{m}^{2}\right.$ weekly during the first 7 weeks, then only on day 1 of each cycle); and Dactinomycin (at $1.5 \mathrm{mg} / \mathrm{m}^{2}$ on day 1) in three weekly cycles with concomitant radiotherapy.

Two weeks subsequent to his first chemotherapy dose he was admitted with neutropenic sepsis and also presented with a House-Brackmann II-III facial nerve palsy but no other middle ear complications. He was started on paediatric doses of intravenous Piperacillin / tazobactam and gentamicin for 5 days as an inpatient prior to being discharged on a paediatric oral dose of ciprofloxacin for the remainder of his chemotherapy course. The facial nerve palsy incompletely resolved with a 2-week course of $3 \mathrm{mg}$ dexamethasone twice daily. He is being followed up on the following schedule: $3-4$ months in the first 2-3 years, then twice a year up to the fifth year,

\section{Literature review}

We searched EMBASE, MEDLINE, UpToDate, CINAHL, TRIP Database, BMJ Best Practice, Google Scholar, Cochrane Database of Systematic Reviews and NICE Evidence Search with the following search terms: rhabdomyosarcoma (RMS); ear; aural; middle ear; inner ear; ear canal, parameningeal; ear neoplasm in July 2018.

Inclusion criteria were: diagnosis of rhabdomyosarcoma of the middle ear; published in a peer reviewed journal; any geographical location or language; any publication date; any age of patient.

In total 11 case reports were found. Of these, there was an equal male-female split. The clinical presentations were similar throughout the case reports, mimicking recurrent otitis media/externa. The average survival across the case reports was 7.2 months. We summarise the case reports in Table 1.

\section{Discussion}

Rhabdomyosarcoma of the middle ear and mastoid is rare $^{2}$. Around $30 \%$ of cases of paediatric rhabdomyosarcoma occur in the head and neck involving the orbits, base of skull, nasal cavity and nasopharyn $\mathrm{x}^{3}$ but only $3 \%$ occur in the ear or mastoid $^{4}$. In total, $63 \%$ of rhabdomyosarcomas occur in children under 10 years old, with a peak between 2 and 5 years old ${ }^{6}$.

Presentation often involves purulent or blood-stained discharge, hearing loss, aural polyps and granulation tissue. Clinical diagnosis is often delayed since the presentation is similar to that of chronic suppurative otitis media ${ }^{7}$. By the time of diagnosis, a facial nerve palsy is usually present and there is involvement of both the middle and external ear and petrous bone betas- $^{8,9}$. Metal tases commonly spread to the lungs, liver, bones and extremities, and are present in approximately $30 \%$ of cases $^{3}$.

According to the International Classification of Rhabdomyosarcoma, these tumours are histopathologically classified into five categories: botryoid, spindle cell, embryonal, alveolar, 


\section{Table 1. Summary of case reports.}

\begin{tabular}{|c|c|c|c|c|c|c|c|c|c|}
\hline Case & Authors & $\begin{array}{l}\text { Patient } \\
\text { sex }\end{array}$ & Age & Journal (year) & Symptom & Investigation & Subtype & Management & Prognosis \\
\hline 1 & Phatak et al. & M & 2 & $\begin{array}{l}\text { Indian Journal } \\
\text { of Otol } 1999\end{array}$ & CNVII palsy & $\mathrm{CT}$ & Embryonal & Surgery + CRT & Alive at $18 \mathrm{mo}$ \\
\hline 2 & Hu et al. & M & 3 & Otol HNS 2002 & Otorrhoea & CT & Embryonal & Surgery + CRT & Alive at $18 \mathrm{mo}$ \\
\hline 3 & Hu et al. & M & 33 & Otol HNS 2002 & $\begin{array}{l}\text { CNVII palsy } \\
+ \text { Otalgia }\end{array}$ & CT & Embryonal & Surgery + CRT & Alive at $24 \mathrm{mo}$ \\
\hline 4 & Abbas et al. & M & 3 & ENT Jour 2005 & Otorrhoea & CT & Embryonal & CRT & Died at $11 \mathrm{mo}$ \\
\hline 5 & Viswanatha & M & 4 & ENT Jour 2007 & $\begin{array}{l}\text { CNVII + } \\
\text { CNVI }\end{array}$ & $\mathrm{CT}$ & Embryonal & Surgery + CRT & Died at 3 mo \\
\hline 6 & Muranjan et al. & $\mathrm{F}$ & 5 & $\begin{array}{l}\text { BMJ Case rep } \\
2014\end{array}$ & $\begin{array}{l}\text { CNVII + } \\
\text { Otorrhoea }\end{array}$ & $\mathrm{CT}+\mathrm{MRI}$ & $\begin{array}{l}\text { Anaplastic } \\
\text { subtype of } \\
\text { embryonal }\end{array}$ & CRT & Died at 5 mo \\
\hline 7 & Vasiwala et al. & M & 6 & $\begin{array}{l}\text { Med J Malaysia } \\
2015\end{array}$ & $\begin{array}{l}\text { CNVII + } \\
\text { Otorrhoea }\end{array}$ & CT & Embryonal & Surgery + CRT & Died at $7 \mathrm{mo}$ \\
\hline 8 & $\begin{array}{l}\text { Bhargava } \\
\text { et al. }\end{array}$ & M & 31 & $\begin{array}{l}\text { J Surg Case } \\
\text { Rep } 2012\end{array}$ & $\begin{array}{l}\text { CNVII + } \\
\text { Otorrhoea }\end{array}$ & CT & Embryonal & Surgery + CRT & Died at 6 mo \\
\hline 9 & Salunke et al. & M & 3 & $\begin{array}{l}\text { J Pediatr } \\
\text { Neurosci } 2012\end{array}$ & $\begin{array}{l}\text { CNVII + } \\
\text { Otalgia + } \\
\text { H/Loss }\end{array}$ & $\mathrm{CT}+\mathrm{MRI}$ & Embryonal & Surgery + CRT & Died at 6 mo \\
\hline 10 & Vegari et al. & $\mathrm{F}$ & 3 & $\begin{array}{l}\text { Case Rep } \\
\text { Otolary } 2012\end{array}$ & Otorrhoea & CT & Embryonal & Surgery & Died at $12 \mathrm{mo}$ \\
\hline 11 & King et al. & $F$ & 2 & $\begin{array}{l}\text { Brachytherapy } \\
2017\end{array}$ & Mass & $\mathrm{CT}+\mathrm{MRI}$ & Botyroid & $\begin{array}{l}\text { Chemo + } \\
\text { Brachy }\end{array}$ & Alive at $8 \mathrm{mo}$ \\
\hline
\end{tabular}

and undifferentiated. Embryonal rhabdomyosarcoma is the most common, accounting for $70-80 \%$, occurring mostly in the orbit and parameninges ${ }^{3}$. Alveolar is the second most common, usually presenting in the deep soft tissues of the extremities ${ }^{4}$.

Risk factors for rhabdomyosarcomas are poorly understood. Epidemiological studies have suggested a link with radiation and recreational drug in utero, lower socioeconomic status and use of antibiotics soon after birth ${ }^{10}$. Several genetic syndromes, including some commonly known to otolaryngologists such as Rubinstein-Taybi syndrome and Beckwith-Wiedemann syndrome, are associated with increased prevalence of rhabdomyosarcoma.

Historically, rhabdomyosarcomas were invariably fatal. Now, 5 -year survival rates of around $80 \%$ have been reported ${ }^{11}$; however, surgical removal is often difficult in head and neck cases given the stage of the neoplasm and anatomy. Consequently, the mainstay of treatment is often chemoradiotherapy. Parameningeal tumours, especially of the middle ear and mastoid, have a poor prognosis because of the proximity to the brain ${ }^{7}$. Of the categories, embryonal have the best prognostic factor and alveolar the worst and children have a better prognosis than adults $^{4}$.

\section{Conclusion}

Rhabdomyosarcoma of the ear is a rare presentation but one which should be considered in young children with recurrent otitis media. If missed, facial nerve involvement is a common as well as local meningeal and distant metastasis. Multidisciplinary involvement and patient education is mandatory in ensuring the highest survival rates. Treatment consists of a combination of surgery, chemotherapy and/or radiotherapy.

\section{Data availability}

All data underlying the results are available as part of the article and no additional source data are required.

\section{Consent}

Written informed consent for publication of their clinical details as obtained from the parent of the patient study. 
1. Ries L, Harkins D, Krapcho M: SEER Cancer Statistics Review. National Cancer Institute, Bethesda. 2003; Accessed 14 December 2017. Reference Source

2. Agarwal NM, Popat VC, Traviad C, et al:: Clinical and histopathological study of mass in ear: a study of fifty cases. Indian J Otolaryngol Head Neck Surg. 2013; 65(Suppl 3): 520-525.

PubMed Abstract | Publisher Full Text | Free Full Text

3. Ferraz-filho J, Felipe LF, Floriano VH, et al:: Clinical and radiological findings of the middle ear' embryonal rhabdomyosarcoma and temporal bone in the children. Int Arch Otorhinolaryngol. 2010; 14(1): 123-126.

Reference Source

4. Shirani S, Alizadeh F, Kashani S: Rhabdomyosarcoma of the Middle and Inner Ear. Iran J Radiol. 2003; 1: 157-160. Reference Source

5. Durve DV, Kanegaonkar RG, Albert D, et al:: Paediatric rhabdomyosarcoma of the ear and temporal bone. Clin Otolaryngol Allied Sci. 2004; 29(1): 32-37. PubMed Abstract | Publisher Full Text

6. Cotton $\mathrm{R}$, Rothschild $\mathrm{M}, \mathrm{Z}$ werdling $\mathrm{T}$ : Tumors of the head and neck in children.
In: Thawley SE, Panje WR, Batsakis JG, Lindberg RD, editors. Comprehensive Management of Head and Neck Tumors 2nd ed. Philadelphia: W.B. Saunders; 1999 1846-1902.

7. Akbar A, Sohail A: Rhabdomyosarcoma of the middle ear and mastoid: a case report and review of the literature. Ear Nose Throat J. 2005; 84(12): 780-784. Publisher Full Text

8. Weiss S, Goldblum J: Soft Tissue Tumurs. 4th ed. St Louis: Mosby; 2001; 785-835.

9. Castillo M, Pillsburg HC 3rd: Rhabdomyosarcoma of the middle ear: imaging features in two children. AJNR Am J Neuroradiol. 1993; 14(3): 730-733. PubMed Abstract

10. Fatih M, Hicks J: Rhabdomyosarcoma in childhood and adolescence: Epidemiology, pathology, and molecular pathogenesis. Uptodate. 2017; Accessed 14 December 2017. Reference Source

11. Devaney KO, Boschman CR, Willard SC, et al.: Tumours of the external ear and temporal bone. Lancet Oncol. 2005; 6(6): 411-420. PubMed Abstract | Publisher Full Text 


\section{Open Peer Review}

\section{Current Peer Review Status:}

\section{Version 1}

Reviewer Report 05 November 2019

https://doi.org/10.5256/f1000research.22599.r54909

(C) 2019 Haymes A. This is an open access peer review report distributed under the terms of the Creative Commons Attribution License, which permits unrestricted use, distribution, and reproduction in any medium, provided the original work is properly cited.

\section{Adam Haymes}

Department of Otolaryngology Surgery, Medway Maritime Hospital, Gillingham, Kent, UK

This article describes a case of botyroid embryonal rhabdomyosarcoma of the right middle ear in a four year old child. It covers the clinical presentation, workup and subsequent management of this rare entity and reviews the pertinent literature of other case descriptions.

The case report is very well written, informative, covers an interesting and unusual topic, and adequately covers all of the objectives set out in the guidelines.

The background of the case's history and progression are described in excellent detail.

Description of the physical examination and workup of the patient are detailed and methodical, as are the descriptions of diagnostic tests, treatments and outcomes.

Emphasis is placed on the rarity of this clinical entity and thus it's contribution to the literature is a useful one. There were no novel treatments in this case report, however the description of the chemotherpay regimen will be useful for other clinicians. Description of the recurrent presentations to the GP and A\&E departments are a sobering reminder of the need for these clinicians to recognise unusual clinical patterns, not rely on previous diagnoses and seek help from specialists early in such scenarios.

Images of the histology would have been a nice to see given the rarity of this clinical entity.

Is the background of the case's history and progression described in sufficient detail? Yes

Are enough details provided of any physical examination and diagnostic tests, treatment given and outcomes?

Yes 


\section{Is sufficient discussion included of the importance of the findings and their relevance to future understanding of disease processes, diagnosis or treatment? Yes}

Is the case presented with sufficient detail to be useful for other practitioners? Yes

Competing Interests: No competing interests were disclosed.

Reviewer Expertise: Otolaryngology, Rhinology, Head \& Neck surgery, Tissue engineering, regenerative medicine

I confirm that I have read this submission and believe that I have an appropriate level of expertise to confirm that it is of an acceptable scientific standard.

Reviewer Report 31 October 2019

https://doi.org/10.5256/f1000research.22599.r54912

(C) 2019 Hickson C. This is an open access peer review report distributed under the terms of the Creative Commons Attribution License, which permits unrestricted use, distribution, and reproduction in any medium, provided the original work is properly cited.

\section{Craig Hickson}

Leicester Royal Infirmary, Leicester, UK

This is a generally well written case report detailing a rare disease process in an unusual anatomical location. It covers pathogenesis, presentation, problems with diagnosis, treatment and prognosis.

It has multiple grammatical errors which need review and correcting:

'Recreational drugs in utero.'

The diagnosis is often delayed and easily misdiagnosed as AN aural polyp

'A four-year-old boy presented with a four-month history of recurrent left ear blood and pus discharge' - please revise to A four-year-old boy presented with a four-month history of recurrent haemo-purulent discharge from the left ear.

In addition I have the following comments/suggestions:

Intra- operatively, a large lesion extending from the middle ear through the tympanic membrane and into the external auditory canal was noted which was resected. The lesion was found to be highly vascular. 
Was it totally resected? Via a tympanotomy? Or was the tissue lateral to the TM resected. If a tympanotomy was performed what was the status of the ossicles?

You say that the facial nerve palsy incompletely resolved. Please give details using HouseBrackmann or other suitable classification.

How do you arrive at '3\% of paediatric rhabdomyosarcoma occurring in the head and neck involving the '?

There are only 11 cases reported. You would need 100/3 = 30 cases or more to be able to state this?

Could intra operation images and high res CT image be included?

Please state the disease free followup to date of your patient.

Please comment on hearing outcome.

There is no mention specific mention of MDT discussion? You state a second opinion was sought but surely this case went through an MDT?

Is the background of the case's history and progression described in sufficient detail? Yes

Are enough details provided of any physical examination and diagnostic tests, treatment given and outcomes?

Partly

Is sufficient discussion included of the importance of the findings and their relevance to future understanding of disease processes, diagnosis or treatment?

Yes

Is the case presented with sufficient detail to be useful for other practitioners?

Partly

Competing Interests: No competing interests were disclosed.

Reviewer Expertise: Otology

I confirm that I have read this submission and believe that I have an appropriate level of expertise to confirm that it is of an acceptable scientific standard.

Author Response 11 Nov 2019

Richard Menzies-Wilson, Whipps Cross University Hospital, London, UK

Many Thanks for your comments. We have adjusted the manuscript to reflect your feedback. 
Competing Interests: No competing interests were disclosed.

Reviewer Report 16 October 2019

https://doi.org/10.5256/f1000research.22599.r54913

(C) 2019 Cunnane M. This is an open access peer review report distributed under the terms of the Creative Commons Attribution License, which permits unrestricted use, distribution, and reproduction in any medium, provided the original work is properly cited.

\section{Max Cunnane}

Royal Sussex County Hospital, Brighton, UK

This is an interesting, concise and well-constructed case report and review of the relevant literature surrounding rhabdomyosarcoma affecting the middle ear. This is a rare entity and as such additional case reports are valuable in adding to the existing literature.

The case report contains adequate description of the patient and detail of the presentation and initial investigations, which would be in line with the reviewers own practice.

The case highlights the need for high clinical suspicion when treating non-resolving recurrent ear infections in children which is a useful message for clinicians.

The literature review results are presented clearly and contain all relevant information regarding the case's reported. However, there is a lack of detail surrounding which chemotherapy/radiotherapy regimes were used. It is also unclear if they were adjuvant or primary treatment modalities for the other cases described.

Is the background of the case's history and progression described in sufficient detail? Yes

Are enough details provided of any physical examination and diagnostic tests, treatment given and outcomes?

Yes

Is sufficient discussion included of the importance of the findings and their relevance to future understanding of disease processes, diagnosis or treatment? Yes

Is the case presented with sufficient detail to be useful for other practitioners? Yes

Competing Interests: No competing interests were disclosed. 
Reviewer Expertise: Working as specialist registrar in otolaryngology. Particular interest include paediatric ENT and laryngology

I confirm that I have read this submission and believe that I have an appropriate level of expertise to confirm that it is of an acceptable scientific standard.

The benefits of publishing with F1000Research:

- Your article is published within days, with no editorial bias

- You can publish traditional articles, null/negative results, case reports, data notes and more

- The peer review process is transparent and collaborative

- Your article is indexed in PubMed after passing peer review

- Dedicated customer support at every stage

For pre-submission enquiries, contact research@f1000.com 